\title{
Pemanfaatan Museum Keraton Sambaliung untuk Meningkatkan Pemahaman Sejarah Siswa
}

\author{
Zulkifli Randa ${ }^{1}$, Ari Sapto ${ }^{1}$, Blasius Suprapta ${ }^{1}$ \\ ${ }^{1}$ Pendidikan Sejarah-Universitas Negeri Malang
}

\begin{tabular}{l}
\hline \hline INFO ARTIKEL \\
\hline Riwayat Artikel: \\
Diterima: $31-10-2019$ \\
Disetujui: $17-04-2020$
\end{tabular}

\section{Kata kunci:}

sambaliung palace; historical understanding; learners;

keraton sambaliung; pemahaman sejarah; peserta didik

\begin{abstract}
The purpose of this study is to describe the potential use of palace palace as a source of learning, and to find out the historical understanding of students of class X Social High School students. The research method uses Mixed Methods with Sequential Exploratory design. Starting with qualitative research and continuing with quantitative research. The instrument used was a questionnaire. Semple of the research are students of class X IPS I of SMAN 4 Berau. The results showed that the potential of Sambaliung Palace is available as a source of historical learning to support the learning process. The results of data analysis showed that the treatment utilizing Sambaliung Palace as a source of learning could increase students' historical understanding with a probability of 0,000 .
\end{abstract}

ABSTRAK

\begin{abstract}
Abstrak: Tujuan penelitian ini untuk mendeskripsikan potensi pemanfaatan meseum keraton sebagai sumber belajar dan untuk mengetahui pemahaman sejarah peserta didik kelas X IPS SMAN. Metode penelitian menggunakan Mixed Methods dengan desain Sequential Exploratory. Dimulai dengan penelitian kualitatif dan dilanjutkan dengan penelitian kuantitatif. Instrumen yang digunakan berupa kuesioner. Sampel penelitian yaitu siswa kelas X IPS I SMAN 4 Berau. Hasil penelitian menunjukkan bahwa potensi museum keraton Sambaliung cukup tersedia sebagai sumber belajar sejarah untuk menunjang proses kegiatan pembelajaran. Hasil analisis data menunjukkan bahwa perlakuan memanfaatkan meseum keraton Sambaliung sebagai sumber belajar dapat meningkatkan pemahaman sejarah siswa peserta didik dengan probabilitas sebesar 0,000 .
\end{abstract}

\author{
Alamat Korespondensi: \\ Zulkifli Randa \\ Pendidikan Sejarah \\ Universitas Negeri Malang \\ Jalann Semarang 5 Malang \\ E-mail: zulkifli.rsman4berau@gmail.com
}

Mata pelajaran sejarah merupakan salah satu wadah untuk mewariskan kebudayaan yang terjadi di masa lalu. Pembelajaran sejarah sebagai salah satu wadah untuk mewariskan kebudayaan tersebut bukan hanya sejarah nasional, tetapi sejarah lokal yang ada di daerah juga perlu disampaikan (Bahri, 2015). Sumber belajar menjadi sangat penting bagi seorang guru karena dapat membuat siswa dapat berkomunikasi dan berinteraksi dengan kegiatan pembelajaran. Sumber belajar dapat dengan mudah dan murah kita dapatkan di lingkungan sekitar kita dengan pengoptimalan yang baik (Nur, 2012). Masalah yang kerap muncul di sekolah yaitu pelajaran sejarah terfokus melalui buku atau kegiatan di dalam kelas sehingga tidak sejalan dengan tujuan belajar yaitu interaksi siswa dengan masalah-masalah baru yang dilakukan di sekolah, lingkungan keluarga dan lingkungan masyarakat (Yusuf dkk, 2018).

Pembelajaran sejarah betujuan untuk membangkitkan kesadaran sejarah nasional, tetapi sebelum mengenal sebuah sejarah yang bersifat nasional siswa hendaknya mengetahui sejarah yang terjadi di lingkungannya. Melalui pembelajaran sejarah local siswa mendapatkan nilai sejarah yang ada disekitarnya. Dengan sejarah lokal, siswa dapat mengetahui tentang fakta sejarah di lingkungan tempat tinggal siswa yang kemudian dilanjutkan dengan fakta sejarah yang besifat nasional (Jumardi, 2017). Sejarah lokal juga dapat berperan menjadi pelestarian warisan budaya pada generasi muda yang didasari pada prinsip bahwa masyarakat mendapatkan nilai positif, yaitu untuk jati diri bangsa, perkembangan ilmu pengetahuan, dan untuk sektor parawisata (Winaya, 2015). Dengan berinteraksi dengan lingkungannya siswa mendapatkan pengetahuan dan pengalaman tentang apa yang terjadi di sekitarnya ataupun di lingkungan sosialnya (Sutarjo, 2013).

Hal penting dalam pembelajaran sejarah yakni dapat menumbuhkan pemahaman kepada siswa tentang bagaimana sejarah terbentuknya bangsa Indonesia dengan proses yang panjang dan masih berlanjut hingga sekarang dan berguna bagi masa yang akan datang (Karyono, 2010). Permasalahan yang muncul dalam pembelajaran sejarah ialah mengenai pengelolaan dan pelestarian budaya kepada generasi muda. Kurangnya pemanfaatan berbagai peninggalan-peninggalan besar di Indonesia juga merupakan sebuah masalah dalam pembelajaran sejarah. seperti peninggalan kerajaan-kerajaan yang ada di Indonesia berupa keraton, candi, dan lain sebagainya (Rosyadi dkk, 2015). Seperti peninggalan kesultanan Sambaliung berupa keraton yang sekarang dialihfungsikan menjadi sebuah museum. 
Mengunjungi suatu museum adalah suatu kegiatan inovatif yang akan menambah pengalaman belajar secara langsung bagi peserta didik. Selain itu, bangunan bersejarah juga membantu peserta didik memahami materi sejarah (Triastuti, 2015). Museum berfungsi untuk memamerkan benda-benda koleksi dari peninggalan masa lalu guna untuk melestarikan warisan budaya yang dapat dimanfaatkan sebagai studi, penelitian, dan rekreasi (Mursi dkk, 2019). Museum hanya dimanfaatkan sebagai tempat penyimpanan dan pemeliharanan benda peninggalan sejarah saja serta hanya sebagai monumen penghias kota bagi sebagian besar masyarakat bahkan kalangan pendidik (Mursidi, 2010). Meseum juga diharapkan menjadi daya tarik untuk para konsumen agar dapat kembali mengunjunginya dan mendapatkan pengetahuan dari museum yang dikunjungi (Harisson, 2004).

Bukti peninggalan sebuah kesultanan di kabupaten Berau ialah sebuah keratin yang terletak di tepi sungai Kelay, kecamatan Sambaliung, Berau. Keratin ini telah dialihfungsikan menjadi museum dan menjadi objek wisata yang menarik di Berau. Koleksi yang menjadi daya tarik yang menarik berupa dua tiang kayu ulin yang bertuliskan aksara asli suku bugis tepat berada disamping kanan museum, isi dari aksara didalam tang kayu tersebut berisikan aturan-aturan bagi rakyat di lingkungan keratin. Koleksi-koleksi bersejarah yang ada di keraton Sambaliung diharapkan bukan hanya sebagai bahan untuk koleksi saja, tetapi juga sebagai sumber informasi dari sejarah masa lampau, menjadi stimulus untuk siswa agar lebih tertarik dengan pembelajaran sejarah, dan dapat meningkatkan pemahaman sejarah.

\section{METODE}

Metode penelitian ini menggunakan metode campuran (Mixed Methods) sequential exploratory yaitu penelitian yang menggabungkan dua penelitian ilmiah kualitatif dan kuantitatif secara berurutan, yang dimulai dengan mmenggunakan metode kualitatif dan dilanjutkan dengan menggunakan kuantitatif (Chrisnathaniel dkk, 2017). Penerapan desain sequential exploratory atau eksploratoris sekuensial adalah proses penelitian diawali dengan kualitatif kemudian kuantitatif. Tahapan awal dari penelitian ini yaitu penelitian kualitatif dengan melakukan observasi dan wawancara untuk mendapatkan data secara mendalam yang kemudian hasil dari penelitian kualitatif tersebut maka akan muncul sebuah praduga dari penulis terhadap sebuah gejala yang terjadi dilapangan. Kemudian pada tahap selanjutnya dibuat sebuah hipotesis guna dapat diuji apakah ada pengaruh antara variabel yang memengaruhi dan variabel yang dipengaruhi (Mulyadi, 2013). Kemudian (Abdillah, 2017) berpendapat bahwa penelitian mix method berguna untuk melengkapi dua metode penelitian, yaitu kualitatif dan kuantitatif sehingga dapat saling menguatkan satu sama lain dari hasil penelitiannya. Sebuah teori atau hasil penelitian tidak muncul sendirinya, tetapi dibangun oleh peneliti dan juga peserta peneliti (Rosli dkk, 2015). Penelitian ini menghubungkan (connecting) data kualitatif dan kuantitatif. Metode kualitatif digunakan untuk memperoleh gambaran mengenai potensi museum keraton Sambaliung yang dapat digunakan sebagai sumber belajar, sedangkan untuk metode kuantitatif untuk mengetahui pemahaman sejarah peserta didik setelah memanfaatkan museum keraton Sambaliung sebagai sumber belajar. Desain kuantitatif dalam penelitian ini adalah desain pre-eksperiment one group pre-test-post-test. sempelnya adalah siswa kelas X IPS 1 SMA Negeri 4 Kabupaten Berau, Kalimantan Timur tahun ajaran 2018/2019 (semester dua/genap). Sampel yang peneliti gunakan adalah keals X IPS 1 yang berjumlah 36 peserta didik.

\section{HASIL}

Hasil penelitian berdasarkan wawancara dengan seluruh informan yang ada baik di museum keraton Sambaliung ataupun di SMAN 4 Berau didapatkan bahwa secara umum sebagian besar potensi museum keraton Sambaliung dapat dimanfaatkan sebagai sumber belajar sejarah, selain itu bahwa ruang singgasana raja, ruang nazar, dan tiang prasasti kayu adalah ruang yang paling berkaitan dengan materi pembelajaran sejarah. Keseluruhan hasil temuan dalam penelitian ini disajikan pada tabel 1 .

\section{Uji Hipotesis}

Sebelum mendapatkan hipotesis dalam penelitian ini, dilakukan uji prasarat terdahulu yaitu uji normalitas pada data kuantitatif. Hasil uji normalitas dapat dilihat pada tabel 2.

Berdasarkan tabel 2 dapat diketahui hasil uji normalitas tes pemahaman sejarah siswa sebelum dan sesudah pembelajaran sejarah dengan uji statistik One-Sample Kolmogorov-Smirnov Test. Hasil uji normalitas pada kelas X IPS 1 untuk pretest pemahaman siswa dengan frekuensi data 36 dengan nilai Asymp. Sig (2-tailed) adalah 0,563 > 0,05 sehingga pretes pemahaman belajar siswa berdistribusi normal. Uji normalitas untuk posttest pemahaman siswa dengan frekuensi data 36 mengungkapkan bahwa nilai Asymp. Sig (2-tailed) adalah 0,558 > 0,05 sehingga data dari posttes pemahaman siswa juga berdistribusi normal. Hasil pengujian perbedaan pretest dan posttest tentang kesadaran sejarah peserta didik di SMAN Berau disajikan pada tabel 3 . 
Tabel 1. Potensi Museum keraton Sambaliung dimanfaatkan sebagai Sumber Belajar Sejarah

\begin{tabular}{|c|c|c|}
\hline \multicolumn{2}{|r|}{ Temuan } & Deskripsi \\
\hline 1. & $\begin{array}{l}\text { Potensi museum Batiwakkal sebagai } \\
\text { sumber sejarah }\end{array}$ & ruang singgasana raja, ruangnazar, dan Tiang Prasasti Kayu \\
\hline 2. & Ruang singgasana raja & $\begin{array}{l}\text { Singgasana / tempat duduk raja di kesultanan Sambaliung biasa dimanfaatkan untuk } \\
\text { acara persta pernikahan kerabat dari kerajaan dan juga acara penting lainnya. } \\
\text { Singgasana ini diselimuti dengan kain kuning dan dilengkapi dengan kida-kida } \\
\text { (berbentuk ukiran daun terbuat dari kuningan yang disambung dengan butiran } \\
\text { manik-manik) }\end{array}$ \\
\hline & Ruang Nazar & $\begin{array}{l}\text { Tempat dimana para kerabat dan keluarga dari kesultanan untuk melakukan nazar. } \\
\text { Nazar itu sendiri adalah sebuah ibadah yang dipanjatkan eseorang kepada Allah } \\
\text { berupa janji jika apa yang ia harapkan terpenuhi atau terkabulkan. }\end{array}$ \\
\hline 4. & Tiang prasasti kayu & $\begin{array}{l}\text { Tiang tersebut bertuliskan huruf lontar Bugis dan huruf Arab berbahasa Melayu. } \\
\text { Dalam tulisan tersebut berisi sebuah titah Raja/Sultan bagaimana berhadapan } \\
\text { dengan Sultan dan menghormati seorang wanita }\end{array}$ \\
\hline
\end{tabular}

Tabel 2. Uji Kenormalan Data

\begin{tabular}{|c|c|c|c|}
\hline \multirow{2}{*}{ No } & \multirow{2}{*}{ Data Penelitian } & \multicolumn{2}{|r|}{ Hasil } \\
\hline & & Frekuensi & Asymp. Sig (2-tailed) \\
\hline 1 & Pretest & 36 & 0,563 \\
\hline 2 & Posttest & 36 & 0,558 \\
\hline
\end{tabular}

Tabel 3. Paired Samples Test

\begin{tabular}{|c|c|c|c|c|c|c|c|c|}
\hline & \multicolumn{5}{|c|}{ Paired Differences } & \multirow[b]{3}{*}{$\mathrm{t}$} & \multirow[b]{3}{*}{ df } & \multirow{3}{*}{$\begin{array}{l}\text { Sig. }(2- \\
\text { tailed) }\end{array}$} \\
\hline & \multirow[t]{2}{*}{ Mean } & \multirow{2}{*}{$\begin{array}{c}\text { Std. } \\
\text { Deviation }\end{array}$} & \multirow{2}{*}{$\begin{array}{l}\text { Std. } \\
\text { Error } \\
\text { Mean }\end{array}$} & \multicolumn{2}{|c|}{$\begin{array}{c}95 \% \text { Confidence Interval } \\
\text { of the Difference }\end{array}$} & & & \\
\hline & & & & Lower & Upper & & & \\
\hline Pair 1 nilaipretest \& nilaiposttest & -26.47222 & 13.15726 & 2.19288 & -30.92400 & -22.02045 & -12.072 & 35 & .000 \\
\hline
\end{tabular}

Berdasarkan tabel 3, dapat diketahui hasil uji paired sample t test anova dua jalur model pembelajaran signifikansi yaitu $0,005<0,05$, artinya ada dampak positif signifikan pemanfaatan museum keraton sambaliung sebagai sumber belajar terhadap perolehan nilai pemahaman sejarah siswa dalam pembelajaran sejarah. Hasil dari uji paired sample t test pemahaman sejarah siswa didapat hasil signifikansi yaitu $0,000<0,05$ sehingga Ho dalam penelitian ini ditolak, berarti ada dampak positif signifikan pemanfaatan sumber belajar museum keraon sambaliung terhadap pemahaman sejarah siswa kelas X IPS 1 SMAN 4 berau dalam pembelajaran sejarah.

\section{PEMBAHASAN}

Pemahaman dalam penelitian ini menekankan pada pemahaman dalam pembelajaran sejarah yang bukan hanya sekedar mengetahui kumpulan bangunan-bangunan peninggalan sejarah masa lalu yang tidak memiliki makna. Peninggalan masa lalu hanya dapat dipahami dengan konteks masa kini dan sebaliknya memahami masa kini hanya dengan sudut pandang masa lalu (Amboro, 2015). Peristiwa masa lalu memiliki makna terhadap kehidupan masa kini. Indonesia dan Belanda memiliki hubungan sejarah yang panjang yang berperan sebagai tanah jajahan. Kenangan akan kejayaan masa lalu begitu membekas di hati masyarakat Indonesia (Purwanto, 2001). Benda-benda yang berada di museum inilah yang menjadi sumber belajar siswa untuk mengetahui persebaran agama islam dan kesultanan sambaliung. Pendapat ini didukung oleh (Dratriarawati, 2014) yang mengatakan beribu-ribu peninggalan sejarah yang berada di Indonesia dapat digunakan sebagai sumber belajar.

Penerapan media pembelajaran yang dilakukan di luar kelas atau museum memiliki pengaruh yang baik terhadap pemahaman siswa. Sesuai dengan hal tersebut (Susanto, 2014) mengungkapkan bahwa apa yang digunakan dalam proses pembelajaran sedikit banyak menentukan pemahaman siswa. Keadaan di lapangan menunjukkan dengan membawa siswa ke sumber belajar secara langsung, siswa lebih aktif dalam bertanya tentang peninggalan-peninggalan masa kesultanan sambaliung kepada ahlinya, siswa dapat lebih memaknai sumber-sumber belajar, mahasiswa dapat menyentuh langsung peninggalanpeninggalan kesultanan Islam yang digunakan sebagai sumber belajar, dan mahasiswa dapat mengambil gambar serta video untuk dijadikan bahan laporan pembelajaran. Dengan kegiatan belajar tersebut siswa akan mudah peham tentang materi 
pembelajaran yang bersifat abstrak menjadi gambaran yang lebih nyata. Kemudian(Martin, 2002)juga menjelaskan bahwa pembelajaran yang dilakukan di luar atau museum memiliki keuntungan antara lain; (1) proses pembelajaran lebih bermakna, (2) aktivitas siswa lebih meningkat; terjadi pembentukan pribadi siswa. Selain itu, (Nasution, 2014) menyatakan bahwa keuntungan model pembelajaran yang dilakukan di sumber belajar secara langsung dirasa lebih bermakna sebab mahasiswa dihadapkan dengan situasi dan keadaan sebenarnya dan kegiatan belajar mahasiswa juga lebih komprehensif sebab dapat dilakukan dengan berbagai cara, seperti mengamati, bertanya, wawancara, menguji fakta, dan lain-lain. Dalam hal ini, siswa sangat dilibatkan langsung dalam memperoleh dan menemukan pengetahuan secara langsung sehingga materi yang didapatkan pada proses pembelajaran dapat tersimpan lebih lama.

Hasil penelitian ini sesuai dengan penelitian yang dilakukan oleh orang lain. Pada penelitian lain yang dilakukan oleh (Kari A, Dietz, 2002) menyimpulkan bahwa penggunaan media museum dalam meningkatkan pemahaman siswa sangat berpengaruh terhadap daya ingat materi belajar siswa. Perbedaan dalam penelitian ini yaitu pada subjek penelitiannya. Selanjutnya, penelitian yang dilakukan oleh (Lucija Andre \& Tracy Durksen, 2016) menyimpulkan bahwa penggunaan media museum dalam meningkatkan pemahaman siswa sangat berpengaruh terhadap peningkatan pemahaman siswa. Hal ini dibuktikan dengan meningkatnya hasil belajar siswa setelah siswa di bawa ke objek belajar secara langsung. Penggunaan media pembelajaran museumsangat menunjang pembelajaran yang ingin meningkatkan pemahaman sejarah siswa. Penggunaan media museum dalam meningkatkan pemahaman siswa telah diteliti oleh beberapa peniliti dan sukses dalam memperbaiki pembelajaran.

Pengaruh pemanfaatan museum keraton Sambaliung sebagai sumber belajar terhadap pemahaman siswa dalam pembelajaran sejarah dapat dilihat pada output hasil uji paired sample t test dengan menggunakan SPSS pada kolom paires sample test. Hasil uji statistik menunjukkan nilai Sig. sebesar 0,000 < 0,05. Hasil tersebut juga dapat disimpulkan bahwa ada pengaruh positif signifikan pemanfaatan museum keraton Sambaliung sebagai sumber belajar terhadap pemahaman siswa dalam pembelajaran Sejarah kelas X IPS I di SMA Negeri 4 Berau. Berdasarkan hasil tersebut maka hipotesis penelitian diterima. Hasil uji statistik ini juga didukung dengan hasil rata-rata pretes pembelajaran lebih tinggi dibandingkan dengan hasil rata rata posttest pembelajaran siswa yang memanfaatan museum keraton Sambaliung sebagai sumber belajar. Dengan demikian, dapat dikatakan bahwa menggunakan museum sebagai sumber belajar siswa dapat memahami dan mengerti makna dari sumbersumber sejarah dengan cara belajar pada objek secara langsung.

\section{SIMPULAN}

Kesimpulan dari hasil penelitian di atas adalah potensi museum keraton Sambaliung cukup tersedia sebagai sumber belajar sejarah untuk menunjang proses kegiatan pembelajaran. Hasil analisis data menunjukkan bahwa perlakuan memanfaatkan museum keratin sambaliung sebagai sumber belajar sejarah dapat meningkatkan pemahaman siswa dengan probabilitas sebesar 0.000 .

Penelitian ini disarankan kepada Dinas Pendidikan agar hasil penelitian ini dapat digunakan sebagai bahan rujukan tentang perencanaan Pendidikan berbasis lingkungan daerah serta disarankan mengedepankan peningkatan kompetensi guru dengan memberikan ruang seluas-luasnya dalam mengembangkan kemampuan.

\section{DAFTAR RUJUKAN}

Abdillah, F. (2017). Revitalisasi Kemampuan Refleksi Mahasiswa Calon Guru Melalui Penulisan Jurnal Perkuliahan PPKN. EduHumaniora | Jurnal Pendidikan Dasar Kampus Cibiru, 9(1), 8. https://doi.org/10.17509/eh.v9i1.6148

Bahri, S. (2015). Gawai Dayak sebagai Sumber Sejarah Lokal Tradisi Masyarakat Indonesia Sebelum Mengenal Tulisan. Jurnal Ilmu-ilmu Sosial, 12(2).

Amboro, K. (2015). Membangun Kesadaran Berawal dari Pemahaman; Relasi Pemahaman Sejarah dengan Kesadaran Sejarah Mahasiswa Program Studi Pendidikan Sejarah FKIP Universitas Muhammadiyah Metro. Historia, 3(2), 109. https://doi.org/10.24127/hj.v3i2.150

Chrisnathaniel, H. C., Mawardi, M. K., Administrasi, F. I., \& Brawijaya, U. (2017). Menciptakan Ruang Pasar Baru Berskala Internasional (Studi Kasus pada PT Kebon Agung). Jurnal administrasi bisnis, 43(1), 50-59.

Dratriarawati, A. (2014). Pemanfaatan Museum Isdiman Ambarawa sebagai Sumber Belajar. Indonesian Journal of History Education, 3(2), 17-21.

Harrison, P., \& Shaw, R. (2004). Consumer Satisfaction and Post-Purchase Intentions: An Exploratory Study of Museum Visitors. International Journal of Arts Management, 6(2), 23-32.

Jumardi, J. (2017). Peranan Pelajaran Sejarah Dalam Pengembangan Karakter Siswa melalui Pembelajaran Berbasis Nilai Sejarah Lokal di SMA Negeri 65 Jakarta Barat. Jurnal Pendidikan Sejarah, 6(2), 70. https://doi.org/10.21009/jps.062.08

Kari A, Dietz. (2002). Influence of teaching in an outdoor classroom on kindergarten children's comprehension and recall of a science lesson. Unpublished Thesis. USA: B.A., University of Lousiana Lafayette.

Kartodirjo S. 1993. Pendekatan Ilmu Sosial Dalam Metodologi Sejarah. Jakarta: Gramedia. 
Karyono. (2010). Pemanfaatan Museum sebagai Media Pembelajaran Untuk Meningkatkan Pemahaman Siswa Terhadap Materi Prasejarah bagi Guru Guru SMA Kota Semarang. Jurnal Abdimas, 14(1).

Lucija Andre \& Tracy Durksen (2016). Museums as Avenues of Learning for Children: A Decade of Research. The Museum Journal and 96 in Journal of Museum Education 20, 47-76.

Mulyadi, M. (2013). Penelitian Kuantitatif dan Kualitatif serta Pemikiran Dasar Menggabungkannya. Jurnal Studi Komunikasi dan Media, 15(1), 128. https://doi.org/10.31445/jskm.2011.150106

Martin, C. A., \& Tulgan, B. 2002. Managing The Generation Mix: From Collision to Collaboration. Human Resource Development.

Mursi A. D., Zafri., \& Ofianto. (2019). Pemanfaatan Museum Adityawarman sebagai Salah Satu Sumber Pembelajaran Sejarah Bagi Siswa SMA Don Bosco Padang. Jurnal Kronologi, 1(1), 46-53.

Mursidi, A. (2010). Pemanfaatan Museum Blambangan sebagai Sumber Belajar Sejarah di Kelas X SMA Negeri Kabupaten Banyuwangi. Jurnal Paramita, 20(2), 190-202.

Nugroho, A., \& Mareza, L. (2016). Pemanfaatan Museum Bri Dan Museum Jenderal Sudirman sebagai Sumber Belajar IPS oleh Siswa dan Guru SD di Purwokerto. Jurnal Ilmiah Kependidikan, IX(2).

Nur, F. M. (2012). Pemanfaatan Sumber Belajar Dalam Pembelajaran Sains Kelas V SD pada Pokok Bahasan Makhluk Hidup dan Proses Kehidupan. JESBIO, 1(1), 14-20.

Purwanto. B. (2001). Memahami Kembali Nasionalisme Indonesia. Jurnal Ilmu Sosial dan Ilmu Politik, 4(3)

Rosli, N., Ambak, K., Daniel, B. D., Prasetijo, J., Tun, U., Onn, H., \& Pahat, B. (2015). The Value of Mixed-Method Research with Families of Children with Autism Spectrum Disorder. Jurnal Teknologi, 1, 1-6.

Rosyadi, K., Rozikin, M., \& Trisnawati. (2015). Analisis Pengelolaan Dan Pelestarian Cagar Budaya Sebagai Wujud Penyelenggaraan Urusan Wajib Pemerintahan Daerah (Studi pada Pengelolaan dan Pelestarian Situs Majapahit Kecamatan Trowulan Kabupaten Mojokerto). Jurnal Administrasi Publik, 2(32), 830-836.

Nasution, A. H., Sejarah, P. P., Indonesia, U. P., \& Lokal, P. S. (2014). Pemanfaatan Situs Kesultanan Deli Dalam. Jurnal Pendidikan Ilmu Sosial. 23(2), 91-98.

Susanto, Heri. 2014. Seputar Pembelajaran Sejarah: Isu Gagasan dan Strategi Pembelajaran. Yogyakarta: Aswaja Pressindo

Sutarjo., Sariyatul \& Agung L. S. (2013). Penerapan Model Problem Based Learning (PBL dengan Media Museum Kars Dalam Pembelajaran IPS untuk Meningkatkan Pemahaman tterhadap Situs Sejarah pada Siswa Kelas VII SMP Negereri 1 Ngodirojo Kanupaten Wonogiri Tahun 2015/2016. Journal of Chemical Information and Modeling, 53(9), 1689-1699. https://doi.org/10.1017/CBO9781107415324.004

Winaya, A. (2015). Peran Museum Majapahit sebagai Mediator Pelestarian Warisan Budaya dan Industri Pembuatan Bata. Amerta, 33(2), 97. https://doi.org/10.24832/amt.v33i2.218

Wiryohandoyo, S. (1998). Pendidikan Ilmu Sosial. Semarang: IKIP Semarang.

Yusuf, M. A., Ibrahim, N., \& Kurniawati. (2018). Pemanfaatan Museum sebagai Sumber Belajar dalam Pembelajaran Sejarah. Visipena, 9(2), 215-235. 